\title{
SARCOCYSTIS NEURONA (PROTOZOA: APICOMPLEXA): DESCRIPTION OF OOCYSTS, SPOROCYSTS, SPOROZOITES, EXCYSTATION, AND EARLY DEVELOPMENT
}

\author{
Author(s): David S. Lindsay, Sheila M. Mitchell , M. C. Vianna, and J. P. Dubey \\ Source: Journal of Parasitology, 90(3):461-465. 2004. \\ Published By: American Society of Parasitologists \\ DOI: http://dx.doi.org/10.1645/GE-230R \\ URL: http://www.bioone.org/doi/full/10.1645/GE-230R
}

BioOne (www.bioone.org) is a nonprofit, online aggregation of core research in the biological, ecological, and environmental sciences. BioOne provides a sustainable online platform for over 170 journals and books published by nonprofit societies, associations, museums, institutions, and presses.

Your use of this PDF, the BioOne Web site, and all posted and associated content indicates your acceptance of BioOne's Terms of Use, available at www.bioone.org/page/terms_of_use.

Usage of BioOne content is strictly limited to personal, educational, and non-commercial use. Commercial inquiries or rights and permissions requests should be directed to the individual publisher as copyright holder. 


\title{
SARCOCYSTIS NEURONA (PROTOZOA: APICOMPLEXA): DESCRIPTION OF OOCYSTS, SPOROCYSTS, SPOROZOITES, EXCYSTATION, AND EARLY DEVELOPMENT
}

\author{
David S. Lindsay, Sheila M. Mitchell, M. C. Vianna*, and J. P. Dubey \\ Center for Molecular Medicine and Infectious Diseases, Department of Biomedical Sciences and Pathobiology, Virginia-Maryland Regional \\ College of Veterinary Medicine, Virginia Tech, 1410 Prices Fork Road, Blacksburg, Virginia 24061-0342. e-mail: lindsayd@vt.edu
}

\begin{abstract}
Equine protozoal myeloencephalitis is a major cause of neurological disease in horses from the Americas. Horses are considered accidental intermediate hosts. The structure of sporocysts of the causative agent, Sarcocystis neurona, has never been described. Sporocysts of $S$. neurona were obtained from the intestines of a laboratory-raised opossum fed skeletal muscles from a raccoon that had been fed sporocysts. Sporocysts were 11.3 by $8.2 \mu \mathrm{m}$ and contained 4 sporozoites. The appearance of the sporocyst residuum was variable. The residuum of some sporocysts was composed of many dispersed granules, whereas some had granules mixed with larger globules. Excystation was by collapse of the sporocyst along plates. The sporocysts wall was composed of 3 layers: a thin electron-dense outer layer, a thin electron-lucent middle layer, and a thick electron-dense inner layer. The sporocyst wall was thickened at the junctions of the plates. Sporozoites were weakly motile and contained a centrally or posteriorly located nucleus. No retractile or crystalloid body was present, but lipidlike globules about $1 \mu \mathrm{m}$ in diameter were usually present in the conoidal end of sporozoites. Sporozoites contained 2-4 electron-dense rhoptries and other organelles typical of coccidian zoites. Sporozoites entered host cells in culture and underwent schizogony within 3 days.
\end{abstract}

Equine protozoal myeloencephalitis caused by Sarcocystis neurona is a major neurological syndrome of horses in the Americas (Dubey, Lindsay, Saville et al., 2001). The parasite was known since the early 1960s but was not named until 1991 when it was isolated and grown in cell culture (Dubey et al., 1991). Horses are considered accidental hosts, and no S. neurona sarcocyst stage has been described in their tissues. This study was conducted to describe the structure of $S$. neurona sporocysts from an experimentally infected definitive host, the Virginia opossum, Didelphis virginiana. This is important because the structure of known $S$. neurona sporocysts has not been reported previously, and the opossum is the definitive host for at least 4 species of Sarcocystis. In addition, we describe the features of excystation and the ultrastructure of S. neurona sporozoites.

\section{MATERIALS AND METHODS}

\section{Sporocysts and excystation}

Sporocysts of the S. neurona SN-37R isolate (Sofaly et al., 2002) were obtained from the intestines of an opossum OHS 30 fed raccoon 2-1 on 14 December 2001. Sporocysts were mixed in at equal volumes of $1.5 \%(\mathrm{w} / \mathrm{v})$ sodium taurocholic acid in Hank's balanced salt solution without calcium and magnesium to contain a final concentration of $0.75 \%(\mathrm{w} / \mathrm{v})$ sodium taurocholic acid. The suspension was then incubated at $37 \mathrm{C}$ in a water bath and examined at 15-min intervals for at least $1 \mathrm{hr}$. Sporocysts were examined using an Olympus BX60 microscope equipped with differential contrast optics and a digital camera. Measurements were obtained from 40 sporocysts using oil emersion and a calibrated ocular micrometer.

\section{Scanning and transmission electron microscopy}

For scanning electron microscopy (SEM), suspensions of sporocysts not processed for excystation were fixed in 3\% glutaraldehyde in 0.1 M phosphate buffer. Samples were washed twice with $0.1 \mathrm{M}$ sodium phosphate buffer ( $\mathrm{pH} 7.4$ ) by centrifugation. Approximately $0.5-0.7 \mathrm{ml}$ of resuspended sporocyst solution was transferred to a $0.2-\mu \mathrm{m}$ polycarbonate filter (Nucelepore, Pleasonton, California) using a 1-ml syringe with positive pressure. The membrane filter disc with attached sporocysts was placed in a petri dish and postfixed with $1 \%$ osmium tetroxide in $0.1 \mathrm{M}$ phosphate buffer for $1 \mathrm{hr}$, washed with $0.1 \mathrm{M}$ phosphate buffer,

Received 30 August 2003; revised 23 October 2003; accepted 24 October 2003.

* Animal Parasite Diseases Laboratory, USDA, Beltsville, Maryland 20705. and dehydrated in a series of ethanols and the Ladd critical point dryer. Samples were then mounted on aluminum stubs, coated with gold (approximately $400 \mathrm{~nm}$ ) in an SPI module sputter coater, and examined with a Phillips 505 scanning electron microscope operating at $30 \mathrm{kV}$.

For transmission electron microscopy (TEM), suspensions of excysted sporocysts, intact sporocysts, and sporozoites were pelleted by centrifugation. The pellet was fixed in $3 \%(\mathrm{v} / \mathrm{v})$ glutaraldehyde in phosphate-buffered saline ( $\mathrm{pH}$ 7.4). Cell pellets were postfixed in $1 \%(\mathrm{w} / \mathrm{v})$ osmium tetroxide in $0.1 \mathrm{M}$ phosphate buffer, dehydrated in a series of ethanols, passed through 2 changes of propylene oxide, and embedded in Poly/Bed 812 resin (Polysciences Inc., Warington, Pennsylvania). Thin sections were stained with uranyl acetate and lead citrate and examined with a Zeiss 10CA TEM operating at $60 \mathrm{kV}$. Digital images were captured using an ATM camera system (Advanced Microscopy Techniques Corp., Danvers, Massachusetts).

\section{Cell culture}

African green monkey (Cercopithecus aethiops) kidney cells (CV-1 cells, ATTC CCL-70, American Type Culture Collection, Manassas, Virginia) were grown to confluence in $25-\mathrm{cm}^{2}$ plastic cell culture flasks in growth media that consisted of $10 \%(\mathrm{v} / \mathrm{v})$ fetal bovine serum in Roswell Park Memorial Institute 1640 medium supplemented with 100 $\mathrm{U}$ penicillin $\mathrm{G} / \mathrm{ml}$ and $100 \mathrm{mg}$ streptomycin $/ \mathrm{ml}$. Cell cultures were incubated at $37 \mathrm{C}$ in a humidified atmosphere containing $5 \% \mathrm{CO}_{2}$ and 95\% air. Development of sporozoites was studied using methods described previously for $S$. neurona merozoites (Lindsay et al., 1999). Cell cultures were inoculated with an undetermined number of sporozoites and examined 24, 54, 60, 72, 77, and $96 \mathrm{hr}$ postinoculation (PI).

\section{RESULTS}

\section{Description}

Sarcocystis neurona Dubey, Davis, Speer, Bowman, De Lahunta, Granstrom, Topper, Hamir, and Suter 1991. (Figs. 1-7)

Fully sporulated oocysts and sporocysts present in intestinal contents of the opossum. Oocyst wall thin and collapsed around sporocysts; oocyst residuum and polar granules absent; 2 sporocysts in each oocyst; sporocysts elongate ellipsoidal $11.3 \pm$ $0.47 \mu \mathrm{m}$ by $8.2 \pm 0.43 \mu \mathrm{m}$ (range, $11-12 \mu \mathrm{m}$ by $7-9 \mu \mathrm{m}$ ) (Figs. 1-4); length-width ratio $1.4 \pm 0.07$ (range, 1.2-1.5); stieda body absent; sporocysts contain 4 sporozoites arranged lengthwise; sporocyst residuum present and variable, residuum of some sporocysts composed of many dispersed granules, whereas some had granules mixed with larger globules; some 


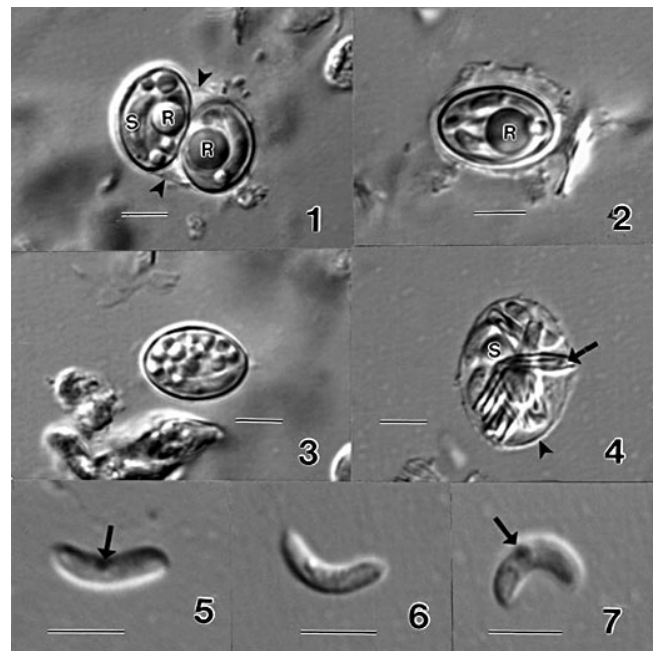

FIGURES 1-7. Differential contrast photomicrographs of Sarcocystis neurona oocysts, sporocysts, and sporozoites. Bar $=5.0 \mu \mathrm{m}$. 1. Intact oocyst. Note the thin oocyst wall (arrowheads) and the 2 sporocysts. A large residuum $(\mathrm{R})$ is present in each sporocyst. Sporozoites (S) are visible in each sporocyst. 2. Individual sporocyst demonstrating a large sporocyst residuum (R). 3. Individual sporocyst demonstrating a dispersed sporocyst residuum. 4. Excysted oocyst. Note the oocyst wall (arrowhead), the sporocyst wall plates (arrow), and the sporozoites (S) 5. Sporozoite with a centrally located nucleus (arrow). 6. Crescentshaped sporozoite. 7. Crescent-shaped sporozoite with a centrally located nucleus (arrow).

intact oocysts had sporocysts with both types of sporocyst residua.

Asexual stages: Schizonts in neural and other tissues of intermediate and aberrant hosts. Sarcocysts in skeletal muscles of intermediate hosts.

Sexual stages: Microgamonts, macrogamonts, and oocysts in cells in the lamina propria of the opossum definitive host.

Type definitive host: Virginia opossum, D. virginiana (see Fenger et al., 1995; Dubey and Lindsay, 1998).

Other definitive hosts: Didelphis albiventris (see Dubey, Lindsay, Kerber et al., 2001).

Type host: Horse, Equus caballus.

Type intermediate host: domestic cats, Felis domesticus (see Dubey et al., 2000).

Other intermediate hosts: Nine-banded armadillos, Dasypus novemcinctus (see Cheadle, Tanhauser et al., 2001); striped skunks, Mephitis mephitis (see Cheadle, Yowell et al., 2001); raccoons, Procyon lotor (see Dubey, Saville et al., 2001); and sea otters, Enhydra lutris (see Dubey, Rosypal et al., 2001).

Type locality: Syntypes deposited in the United States National Parasite Collection (USNPC), Beltsville, Maryland. USNPC 18450 were from a horse from Ohio (Dubey et al., 1974).

Other localities: All of the Americas were Didelphis species are present.

Material deposited: Phototype (see Bandoni and Duszynski, 1988 ) of sporulated $S$. neurona sporocysts are deposited in the USNPC. USNPC 092921.00. Formalin-fixed sporocysts deposited as USNPC 092920.00. Histologic section of tongue from an experimentally infected cat containing $S$. neurona sarcocysts (Dubey et al., 2000) deposited as USNPC 092918.00.

\section{Remarks}

Sarcocystis neurona was originally described from schizonts and merozoites present in neural tissues of horses (Dubey et al., 1991). The opossum was later identified as the definitive host (Fenger et al., 1995; Dubey and Lindsay, 1998). Later, cats (Dubey et al., 2000) and striped skunks (Cheadle, Yowell et al., 2001) were found to be suitable experimental intermediate hosts, and nine-banded armadillos (Cheadle, Tanhauser et al., 2001), raccoons (Dubey, Saville et al., 2001), and sea otters (Dubey, Rosypal et al., 2001) were found to be natural intermediate hosts.

Cheadle, Dame et al. (2001) examined sporocysts of several species of Sarcocystis from naturally infected $D$. virginiana. They used molecular methods to determine which species of Sarcocystis was present, and they indicated that the sporocysts of $S$. neurona were 10.7 by $7.0 \mu \mathrm{m}$. This is smaller than the 11.3 - by $8.2-\mu \mathrm{m}$ measurements we report in the present study of experimentally produced $S$. neurona sporocysts.

\section{Excystation}

Excystation occurred within $15 \mathrm{~min}$. The percent excystation was not determined, but it was estimated at $10-20 \%$ by $1 \mathrm{hr}$. Sporozoites were released from sporocysts by collapse of the sporocyst wall along platelike junctions (Fig. 4). Excysted sporozoites were crescent shaped (Figs. 5-7) and weakly or nonmotile in the excystation solution. The nucleus was in the posterior one-half of the sporozoite. No typical coccidial refractile body was present in sporozoites. However, many sporozoites contained 1 or more granules about $1 \mu \mathrm{m}$ in diameter. These granules were usually in the anterior portion of the sporozoites.

\section{In vitro cultivation}

Sporozoites were seen inside CV-1 cells at $24 \mathrm{hr}$. Developmental stages were usually adjacent to the host cell nucleus. At 54 and $60 \mathrm{hr}$, the sporozoite nucleus became enlarged and a few early schizonts were seen at $60 \mathrm{hr}$ PI. Mature schizonts with merozoites were identified 72 days PI. Numerous schizonts were present 96 days PI. Development was asynchronous.

\section{Ultrastructure}

The junctions of sporocyst wall plates were readily observed using SEM (Fig. 8). The sporocyst wall was composed of 3 layers (Fig. 9): an electron-dense outer layer that was thin and often difficult to observe, an electron-lucent middle layer that was $50 \pm 9 \mathrm{~nm}(\mathrm{~N}=8)$, and an electron-dense inner layer that was $135 \pm 16 \mathrm{~nm}(\mathrm{~N}=7)$. The wall was thickened to $242 \pm$ $35 \mathrm{~nm}(\mathrm{~N}=12)$ at the junction of the plates, and a liplike extension of the inner portion of the sporocyst wall was present at the junction (Fig. 9).

When viewed using TEM, sporozoites contained 2-4 electron-dense rhoptres and other organelles typical of coccidian zoites (Figs. 10-12). Sporozoites were $1.7 \pm 0.2 \mu \mathrm{m}(\mathrm{N}=15)$ wide in the region of the nucleus. Micronemes and dense granules were more numerous in the anterior portion of the sporozoites. Lipidlike bodies were observed in many sporozoites (Figs. 10,11). They were usually anterior to the nucleus and were $0.3-0.9 \mu \mathrm{m}$ in diameter. If more than 1 lipidlike body was present, then they could be found anterior and posterior to the 


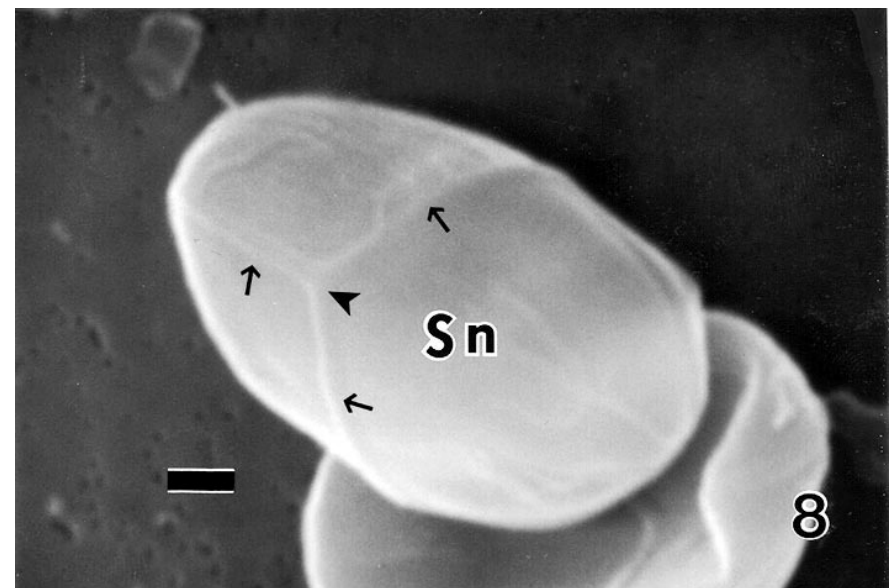

FIGURE 8. Scanning electron photomicrograph of a Sarcocystis neurona sporocyst $(\mathrm{Sn})$. Note the sporocyst wall plates (arrows) and the junction of sporocyst wall plates (arrowhead). Bar $=1 \mu \mathrm{m}$.

nucleus. The posterior portion on many sporozoites contained a posterior pore (Fig. 10).

\section{DISCUSSION}

Sarcocystis neurona is unusual in that molecular means of diagnosis were developed for its sporocysts before its life cycle was elucidated (Tanhauser et al., 1999). The opossum is a definitive host for at least 4 named species of Sarcocystis, and these molecular tools were extremely useful in determining the natural intermediate hosts of $S$. neurona. Cheadle, Dame et al. (2001) found 5 structural types of sporocysts in naturally infected Virginia opossums. They commented that the appearance of the sporocysts residuum was variable in the species they

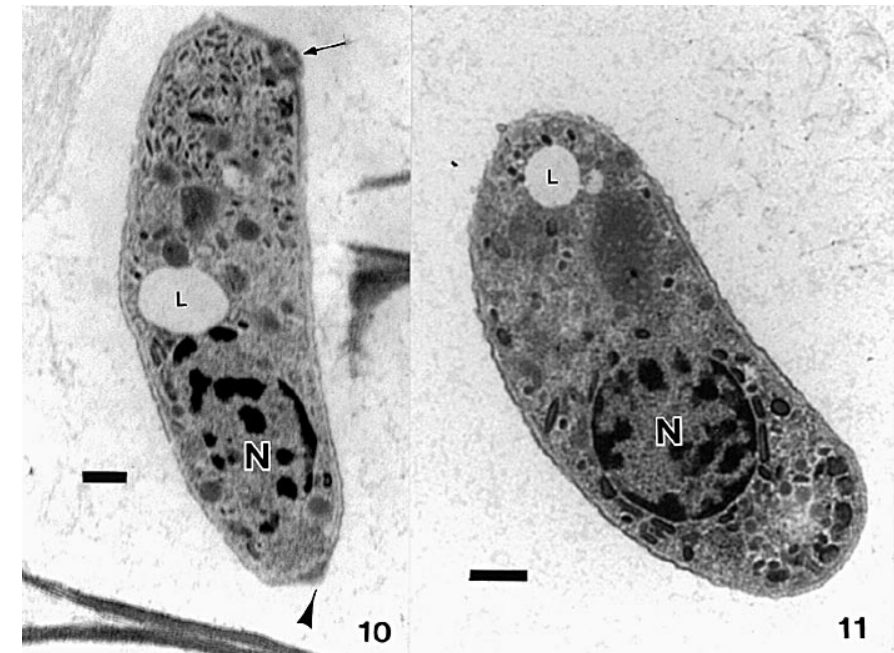

FiguRES 10-11. Transmission electron photomicrograph of sporozoites of Sarcocystis neurona. 10. Sporozoite demonstrating a conoid (arrow), a lipidlike body (L), a nucleus $(\mathrm{N})$, and posterior pore (arrowhead). Bar $=0.5 \mu \mathrm{m}$. 11. Sporozoite demonstrating a nucleus $(\mathrm{N})$ and a lipidlike body (L). Bar $=0.5 \mu \mathrm{m}$.

studied. This is in agreement with our description of the variable appearance of the residuum of $S$. neurona sporocysts from an experimentally infected opossum.

The excystation process of $S$. neurona sporocysts is similar to that described for other Sarcocystis species (Box et al., 1980; Cawthorn et al., 1986; Strohlein and Prestwood, 1986). This mode of excystation is present in all isosporid coccidia that lack a Steida body in their sporocysts (see Lindsay et al., 1997). Murphy and Mansfield (1999) used a mechanical method of shearing sporocysts between glass slides to excyst sporocysts

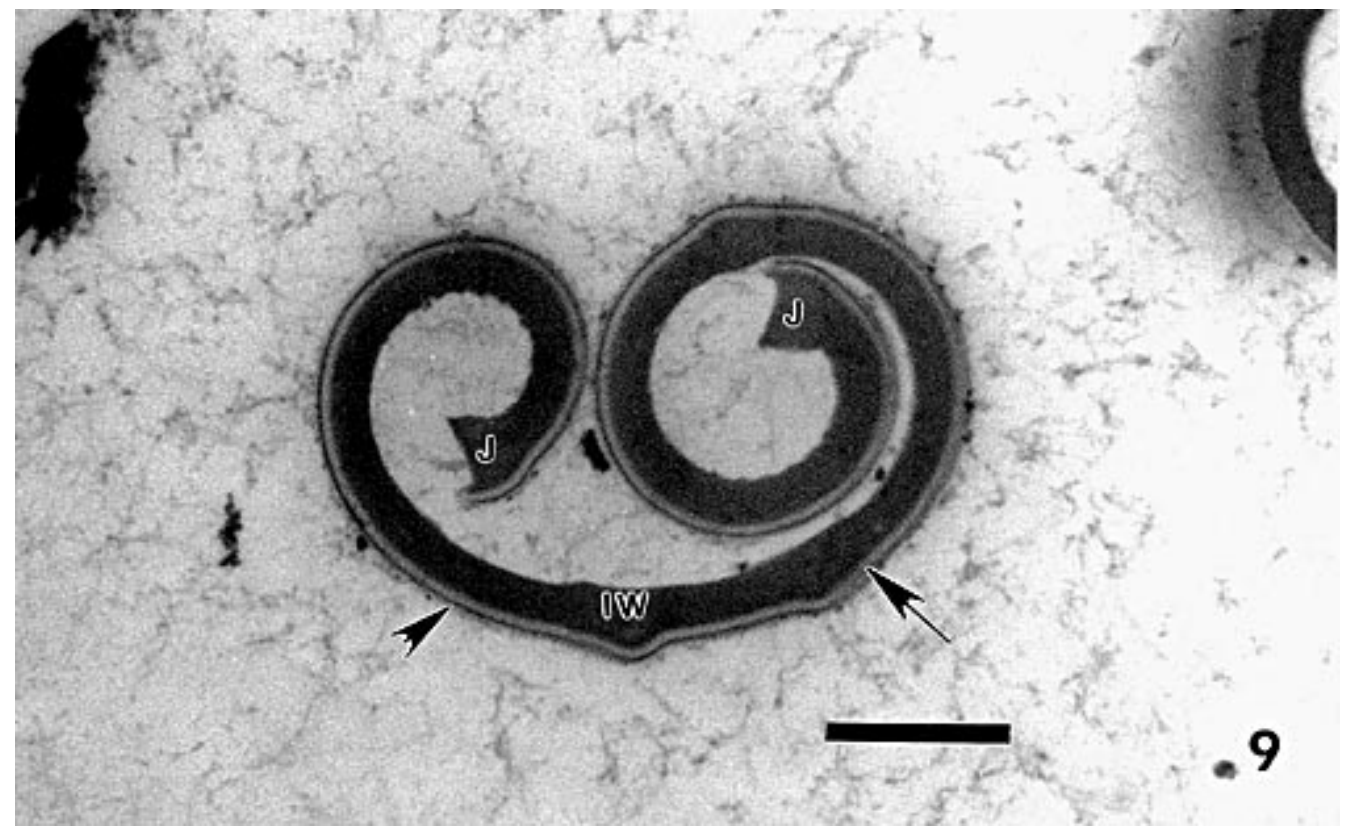

FIGURE 9. Transmission electron photomicrograph of a sporocyst wall of Sarcocystis neurona. Note the thin outer electron-dense layer (arrowhead), the thin electron-lucent middle layer (arrow), and the thick electron-dense inner layer (IW). Note the liplike extension at the sporocyst wall plate at the junction $(\mathrm{J})$. Bar $=500 \mathrm{~nm}$. 


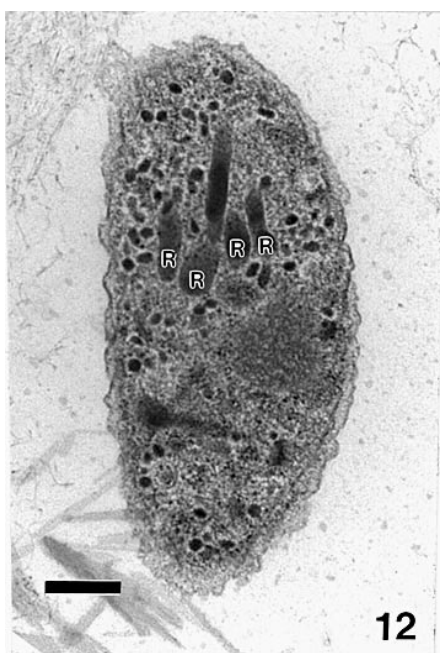

FIGURE 12. Transmission electron photomicrograph of a sporozoite of Sarcocystis neurona demonstrating 4 electron-dense rhoptries (R). Bar $=0.5 \mu \mathrm{m}$

of $S$. neurona and $S$. falcatula. They did not report observations on the mode of induced excystation or structure of excysted sporozoites.

Few reports exist on the ultrastructure of sporozoites of Sarcocystis species. The sporozoites of $S$. cruzi have crystalloid bodies but not refractile or lipidlike bodies (Dubey et al., 1989). Speer and Dubey (2001) described the structure of S. neurona merozoites and Dubey, Lindsay, Fritz et al. (2001) described the structure of $S$. neurona bradyzoites. Sarcocystis neurona bradyzoites contained approximately 2 rhoptries (Dubey, Lindsay, Fritz et al., 2001), whereas S. neurona sporozoites contained 2-4 rhoptries in the present study, and $S$. neurona merozoites do not have rhoptries (Speer and Dubey, 2001). Lipidlike bodies are present in both sporozoites and merozoites and probably bradyzoites as are all other organelles typical for coccidial invasive stages.

Speer, Whitmire et al. (1986) were the first to obtain schizogony of a Sarcocystis species $(S$. cruzi) in cell culture from sporozoites. They determined that host cell type was a limiting factor in the development of sporozoites. Since that time, others have conducted similar studies with sporozoites of other Sarcocystis species (Speer, Cawthorn et al., 1986; Jakel et al., 1997; Murphy and Mansfield, 1999). Andrews et al. (1990) were the first to demonstrate that some Sarcocystis species could develop continuously in cell cultures. Lindsay et al. (1999) described the in vitro development of $S$. neurona merozoites and compared it with that of merozoites of $S$. falcatula. Murphy and Mansfield (1999) achieved successful development of $S$. neurona sporozoites to schizonts in an equine dermal cell line using sporozoites that were excysted using mechanical pressure. They did not describe the time of appearance or structure of schizonts. Sporozoites of $S$. neurona excysted using the more traditional methods employed in the present study were able to penetrate and develop in CV-1 cells in the present study. The timing and appearance of $S$. neurona schizonts using sporozoites as inoculum were similar to our previous studies using merozoites as inoculum (Lindsay et al., 1999).

\section{ACKNOWLEDGMENTS}

This study was supported in part by USDA/CSREES Animal Health and Disease grant VA-137180 to D.S.L. S.M.M. was supported by a scholarship from Bayer HealthCare Animal Health.

\section{LITERATURE CITED}

Andrews, C. D., R. FAyer, And J. P. Dubey. 1990. Continuous in vitro cultivation of Sarcocystis cruzi. Journal of Parasitology 76: 254255 .

BANDONI, S. M., AND D. W. DuszYnSKI. 1988. A plea for improved presentation of type material for coccidia. Journal of Parasitology 74: 519-523.

Box, E. D., A. A. Marchiondo, D. W. Duszynski, and C. P. Davis. 1980. Ultrastructure of Sarcocystis sporocysts from passerine birds and opossums: Comments on classification of the genus Isospora. Journal of Parasitology 66: 68-74.

Cawthorn, R. J., D. W. Reduker, C. A. Speer, and J. P. Dubey. 1986. In vitro excystation of Sarcocystis capracanis, Sarcocystis cruzi and Sarcocystis tenella (Apicomplexa). Journal of Parasitology 72: 880-884.

Cheadle, M. A., J. B. Dame, And E. C. Greiner. 2001. Sporocyst size of isolates of Sarcocystis shed by the Virginia opossum (Didelphis virginiana). Veterinary Parasitology 95: 305-311.

, S. M. Tanhauser, J. B. Dame, D. C. Sellon, D. Hines, P. E. Ginn, R. J. MacKay, And E. C. Greiner. 2001. The nine-banded armadillo (Dasypus novemcinctus) is an intermediate host for Sarcocystis neurona. International Journal for Parasitology 31: 330335.

, C. A. Yowell, D. C. Sellon, M. Hines, P. E. Ginn, A. E. Marsh, J. B. Dame, And E. C. Greiner. 2001. The striped skunk (Mephitis mephitis) is an intermediate host for Sarcocystis neurona. International Journal for Parasitology 31: 843-849.

Dubey, J. P., G. W. Davis, A. Koestner, and K. Kiryu. 1974. Equine encephalomyelitis due to a protozoan parasite resembling Toxoplasma gondii. Journal of the American Veterinary Medical Association 165: 249-255.

, S. W. Davis, C. A. Speer, D. D. Bowman, A. De Lahunta, D. E. Granstrom, M. J. Topper, A. N. Hamir, and M. M. Suter. 1991. Sarcocystis neurona n. sp. (Protozoa: Apicomplexa), the etiologic agent of equine protozoal myeloencephalitis. Journal of Parasitology 77: 212-218.

, AND D. S. LiNDSAY. 1998. Isolation of Sarcocystis neurona from opossum (Didelphis virginiana) faeces in immunodeficient mice and its differentiation from Sarcocystis falcatula. International Journal for Parasitology 28: 1823-1828.

$\longrightarrow$, D. FRITZ, AND C. A. SPEER. 2001. Structure of Sarcocystis neurona sarcocysts. Journal of Parasitology 87: 13231327.

. H. KWOK, S. K. Shen, And B. M. Rosenthal. 2001. First isolation of Sarcocystis neurona from the South American opossum, Didelphis albiventris, from Brazil. Veterinary Parasitology 95: 295-304.

W. J. A. Saville, S. M. Reed, D. E. Granstrom, And C. A. SPEER. 2001. A review of Sarcocystis neurona and equine protozoal myeloencephalitis (EPM). Veterinary Parasitology 95: 89-132.

, A. C. Rosypal, B. M. Rosenthal, N. J. Thomas, D. S. LindSay, J. F. StaneK, W. J. A. Saville, and S. M. Reed. 2001. Sarcocystis neurona infections in Sea otters (Enhydra lutris nereis): Evidence for natural infections with sarcocysts and transmission of infection to opossums (Didelphis virginiana). Journal of Parasitology 87: 1387-1393.

, W. J. A. Saville, D. S. Lindsay, R. W. Stich, J. F. Stanek, C. A. Speer, B. M. Rosenthal, C. J. Nuoku, S. K. Shen, and S. M. REED. 2000. Completion of the life cycle of Sarcocystis neurona. Journal of Parasitology 86: 1276-1280.

, - J. F. Stanek, D. S. Lindsay, B. M. Rosenthal, M. Olglesbee, A. C. Rosypal, C. J. Nuoku, R. W. Stich, O. C. H. Kwok, S. K. Shen, A. N. Hamir, and S. M. Reed. 2001. Sarcocystis neurona infections in raccoons (Procyon lotor): Evidence for natural infection with sarcocysts, transmission of infection to opos- 
sums (Didelphis virginiana), and experimental induction of neurologic disease in raccoons. Veterinary Parasitolology 100: 117129.

, C. A. Speer, AND R. FAyer. 1989. Sarcocystosis of animals and man. CRC Press, Boca Raton, Florida, 215 p.

Fenger, C. K., D. E. Granstrom, J. L. Langemeier, S. Stamper, J. M. Donahue, J. S. Patterson, A. A. Gajadhar, J. V. Marteniuk, Z. XiaOmin, AND J. P. DubeY. 1995. Identification of opossums ( $D i$ delphis virginiana) as the putative definitive host of Sarcocystis neurona. Journal of Parasitology 81: 916-919.

Jakel, T., M. Henke, B. Weingarten, D. Kliemt, and S. Seidinger. 1997. In vitro cultivation of the vascular phase of Sarcocystis singaporensis. Journal of Eukaryotic Microbiology 44: 293-299.

Lindsay, D. S., J. P. Dubey, And B. L. Blagburn. 1997. Biology of Isospora spp. from humans, nonhuman primates, and domestic animals. Clinical and Microbiology Reviews 10: 19-34.

- , K. M. Horton, And D. D. Bowman. 1999. Development of Sarcocystis falcatula in cell cultures demonstrates that it is different from Sarcocystis neurona. Parasitology 118: 227-233.

Murphy, A. J., And L. M. Mansfield. 1999. Simplified technique for isolation, excystation, and culture of Sarcocystis species from opossums. Journal of Parasitology 85: 979-981.

Speer, C. A., R. J. CAwthorn, AND J. P. Dubey. 1986. In vitro cultivation of the vascular phase of Sarcocystis capracanis and Sarcocystis tenella. Journal of Protozoology 33: 486-490.
AND J. P. DuBEy. 2001. Ultrastructure of schizonts and merozoites of Sarcocystis neurona. Veterinary Parasitology 95: 263271.

, W. M. Whitmire, D. W. Reduker, and J. P. Dubey. 1986. In vitro cultivation of meronts of Sarcocystis cruzi. Journal of Parasitology 72: 677-683.

Sofaly, C. D., S. M. Reed, J. C. Gordon, J. P. Dubey, M. L. Ogleebee, C. J. NJoku, D. L. Grover, and W. J. Saville. 2002. Experimental induction of equine protozoan myeloencephalitis (EPM) in the horse: Effect of Sarcocystis neurona sporocyst inoculation dose on the development of clinical neurologic disease. Journal of Parasitology 88: 1164-1170.

Strohlein, D. A., And A. K. Prestwood. 1986. In vitro excystation and structure of Sarcocystis suicanis Erber, 1977, sporocysts. Journal of Parasitology 72: 711-715.

Tanhauser, S. M., M. A. Cheadle, E. T. Massey, B. A. Mayer, D. E. Schroedter, J. B. Dame, E. C. Greiner, and R. J. MacKay. 2001. The nine-banded armadillo (Dasypus novemcinctus) is naturally infected with Sarcocystis neurona. International Journal for Parasitology 31: 325-329.

C. A. Yowell, T. J. Cutler, E. C. Greiner, R. J. MacKay, AND J. B. DAME. 1999. Multiple DNA markers differentiate Sarcocystis neurona and Sarcocystis falcatula. Journal of Parasitology 85: $221-228$. 